\title{
Sources, compositions, and optical properties of humic-like substances in Beijing during the 2014 APEC summit: Results from dual carbon isotope and Fourier-transform ion cyclotron resonance mass spectrometry analyses ${ }^{\hbar 2}$
}

\author{
Yangzhi Mo ${ }^{\text {a, e }}$, Jun $\mathrm{Li}^{\text {a, * }}$, Bin Jiang a, Tao Su ${ }^{\text {a, e }}$, Xiaofei Geng ${ }^{\text {a, e }}$, Junwen Liu ${ }^{\text {a }}$, \\ Haoyu Jiang ${ }^{\text {a, e }}$, Chengde Shen ${ }^{\mathrm{b}}$, Ping Ding ${ }^{\mathrm{b}}$, Guangcai Zhong ${ }^{\mathrm{a}}$, Zhineng Cheng ${ }^{\mathrm{a}}$, \\ Yuhong Liao ${ }^{a}$, Chongguo Tian ${ }^{c}$, Yingjun Chen ${ }^{\mathrm{d}}$, Gan Zhang ${ }^{\mathrm{a}}$ \\ a State Key Laboratory of Organic Geochemistry, Guangzhou Institute of Geochemistry, Chinese Academy of Sciences, Guangzhou, 510640, China \\ b State Key Laboratory of Isotope Geochemistry, Guangzhou Institute of Geochemistry, Chinese Academy of Sciences, Guangzhou, 510640, China \\ ${ }^{\mathrm{c}}$ Key Laboratory of Coastal Zone Environmental Processes and Ecological Remediation, Yantai Institute of Coastal Zone Research, Chinese Academy of \\ Science, Yantai, 264003, China \\ d College of Environmental Science and Engineering, Tongji University, Shanghai, 200092, China \\ e University of Chinese Academy of Sciences, Beijing, 100049, China
}

\section{A R T I C L E I N F O}

\section{Article history:}

Received 3 January 2018

Received in revised form

6 April 2018

Accepted 6 April 2018

Available online 16 April 2018

\section{Keywords:}

Asia-Pacific Economic Cooperation

Brown carbon

Carbon isotope

Fourier-transform ion cyclotron resonance

mass spectrometry

Humic-like substances

\begin{abstract}
A B S T R A C T
Humic-like substances (HULIS) are a class of high molecular weight, light-absorbing compounds that are highly related to brown carbon $(\mathrm{BrC})$. In this study, the sources and compositions of HULIS isolated from fine particles collected in Beijing, China during the 2014 Asia-Pacific Economic Cooperation (APEC) summit were characterized based on carbon isotope $\left({ }^{13} \mathrm{C}\right.$ and $\left.{ }^{14} \mathrm{C}\right)$ and Fourier-transform ion cyclotron resonance mass spectrometry (FT-ICR MS) analyses, respectively. HULIS were the main light-absorbing components of water-soluble organic carbon (WSOC), accounting for $80.2 \pm 6.1 \%$ of the WSOC absorption capacity at $365 \mathrm{~nm}$. The carbon isotope data showed that HULIS had a lower non-fossil contribution $(53 \pm 4 \%)$ and were less enriched with ${ }^{13} \mathrm{C}(-24.2 \pm 0.6 \%)$ relative to non-HULIS $(62 \pm 8 \%$ and $-20.8 \pm 0.3 \%$, respectively). The higher relative intensity fraction of sulfur-containing compounds in HULIS before and after APEC was attributed to higher sulfur dioxide levels emitted from fossil fuel combustion, whereas the higher fraction of nitrogen-containing compounds during APEC may have been due to the relatively greater contribution of non-fossil compounds or the influence of nitrate radical chemistry. The results of investigating the relationships among the sources, elemental compositions, and optical properties of HULIS demonstrated that the light absorption of HULIS appeared to increase with increasing unsaturation degree, but decrease with increasing oxidation level. The unsaturation of HULIS was affected by both sources and aging level.
\end{abstract}

() 2018 Elsevier Ltd. All rights reserved.

\section{Introduction}

Organic aerosols (OAs) comprise a substantial fraction of fine particulate matter, which has traditionally been assumed to exert a cooling effect due to light scattering (Andreae and Gelencser, 2006; Laskin et al., 2015). However, studies over the past decade have

\footnotetext{
This paper has been recommended for acceptance by Charles Wong.

* Corresponding author.

E-mail address: junli@gig.ac.cn (J. Li).
}

shown that certain colored organic compounds absorb radiation efficiently, predominantly in the near-ultraviolet (UV) spectral region. These colored organic compounds are known as brown carbon $(\mathrm{BrC})$ and have a significant impact on the radiative balance of the Earth (Bahadur et al., 2012; Chung et al., 2012). Based on water solubility, $\mathrm{BrC}$ can be operationally separated into water soluble and water insoluble BrC (Cheng et al., 2016; Zhang et al., 2013). Studies have found that humic-like substances (HULIS) are highly linked to BrC (Andreae and Gelencser, 2006; Hoffer et al., 2006; Laskin et al., 2015), and are responsible for more than 70\% of the UV 
absorption of water-soluble BrC (Varga et al., 2001). The optical properties of $\mathrm{BrC}$ are strongly influenced by various factors, including their source (Du et al., 2014; Zhang et al., 2011), atmospheric aging processes (Lambe et al., 2013; Lee et al., 2014; Zhong and Jang, 2014), combustion conditions (Chen and Bond, 2010; Saleh et al., 2014), and molecular weight (MW) (Di Lorenzo and Young, 2016). Because HULIS are a major component of $\mathrm{BrC}$, investigating the relationships among their sources, elemental compositions, and optical properties will improve our understanding of the evolution of $\mathrm{BrC}$ absorption.

Radiocarbon $\left({ }^{14} \mathrm{C}\right)$ analysis is a powerful tool that can quantitatively differentiate and determine fossil (i.e., coal, diesel, and gasoline) and non-fossil (i.e., biomass burning and cooking) sources of carbonaceous particles, because ${ }^{14} \mathrm{C}$ is completely depleted in fossil sources due to radioactive decay, whereas non-fossil sources contain ${ }^{14} \mathrm{C}$ levels similar to those of atmospheric carbon dioxide $\left(\mathrm{CO}_{2}\right)$ (Szidat, 2009; Szidat et al., 2004). Stable carbon isotopes $\left({ }^{13} \mathrm{C} /{ }^{12} \mathrm{C}\right)$ not only provide source information, but also reflect the atmospheric processing of organic carbon (OC). In general, secondary organic aerosol (SOA) formation results in the depletion of ${ }^{13} \mathrm{C}$ in the particle phase, because compounds with lighter isotopes are expected to react faster (Rudolph et al., 2000). Meanwhile, in the further oxidation processes in the particle phase, ${ }^{13} \mathrm{C}$ is enriched in the residual aged organic compounds. For example, diacids were found to have higher $\delta^{13} \mathrm{C}$ values with decreases in carbon numbers, suggesting that the photochemical breakdown of higher diacids releases ${ }^{12} \mathrm{C}$-enriched $\mathrm{CO} / \mathrm{CO}_{2}$ during atmospheric oxidation reactions (Aggarwal and Kawamura, 2008; Wang and Kawamura, 2006). The gap in $\delta^{13} \mathrm{C}$ between water-soluble OC (WSOC) and elemental carbon (EC) increases due to the photochemical aging of aerosols during long-range transport (Bosch et al., 2014). Combining radiocarbon and stable carbon analyses facilitates the determination of sources and atmospheric processes of carbonaceous aerosols, and has been applied to various carbon species, including OC (Sheesley et al., 2012), EC (Bosch et al., 2014), WSOC (Kirillova et al., 2014b), and water-insoluble OC (WISOC) (Kirillova et al., 2013); however, only one study has applied this method to HULIS (Song et al., 2012).

Electrospray ionization (ESI) coupled with Fourier-transform ion cyclotron resonance mass spectrometry (FT-ICR MS) is widely used to analyze complex organic species from various sources, including aerosols (Jiang et al., 2016), rainwater (Altieri et al., 2009), soil (Kramer et al., 2004), and petroleum (Rodgers and Marshall, 2007). The ultrahigh resolving power of FT-ICR MS can be used to assign accurate molecular formulas to thousands of compounds in a sample, but cannot provide structural information, because a single molecular formula can represent several structural isomers. However, fundamental information such as elemental composition, double-bond equivalent (DBE), and elemental ratios can be obtained from the molecular formulas, making FT-ICR MS a highly useful tool for characterizing HULIS.

The Asia-Pacific Economic Cooperation (APEC) summit was held in Beijing, China, from November 5-12, 2014. To guarantee good air quality for the APEC summit, a comprehensive set of strict emissions reduction measures were taken to control air pollution in Beijing and the surrounding regions from November 1-12, which included suspending work at construction sites, reducing half of the city's vehicles in operation by alternating odd and even license plate numbers, halting production in polluting factories, and forbidding open or domestic biomass combustion. These emissions control measures provided a unique opportunity to study the responses of HULIS sources, compositions, and optical properties to these short-term reduction measures. Our previous work has quantified the contributions of fossil and non-fossil sources to different carbonaceous fractions using radiocarbon analysis (i.e., total carbon [TC], OC, WSOC, WIOC, and EC) (Liu et al., 2016a). Compared to our previous study, we determined the $\delta^{13} \mathrm{C}$ and $\Delta{ }^{14} \mathrm{C}$ of HULIS and non-HULIS in the same sample set to identify atmospheric processes and sources. In this study, we put our emphases on the isotope-based sources $\left(\delta^{13} C\right.$ and $\left.\Delta^{14} C\right)$, compositions, and optical properties of HULIS before, during, and after the APEC summit in detail to investigate the influence of emissions control measures and meteorological conditions. We also examined the relationships between the light absorption capacity of HULIS and their composition, oxidation level, and sources to identify factors affecting the light absorption capacity of HULIS.

\section{Materials and methods}

\subsection{Sampling}

Aerosol fine particulate matter $\left(\mathrm{PM}_{2.5}\right)$ samples were collected from October 25 to November 29, 2014, in Huairou District, Beijing, China $\left(40.4^{\circ} \mathrm{N}, 116.7^{\circ} \mathrm{E}\right)$, as described previously (Liu et al., 2016a). Sample collection was conducted at approximately 12-h intervals using a high-volume air sampler (1000 L/min), beginning at 09:00 LT and 21:00 LT for daytime and nighttime samples, respectively. In total, we collected 64 samples during this period, including 16 short time scale samples (3-6h). In this study, we selected 42 samples with a sampling time of $12 \mathrm{~h}$ for further analysis. Except for November 11, at least one sampling was conducted per day. The samples used for carbon isotopic analysis and FT-ICR MS analysis were from October 25-27, November 5-7, and November 18-20, 2014, which represented the before, during, and after APEC periods, respectively. According to our previous study (Liu et al., 2016a), the air masses of the selected samples were mainly from the west and north before the APEC summit, from the north during the APEC summit, and from the west after the APEC summit. Therefore, the selected samples were less affected by populated industrial regions located south of Beijing. A recent modeling study revealed that local emissions control measures contributed the most to pollution reduction during APEC (Liu et al., 2017). Therefore, variations in the sources and elemental compositions of the selected samples were predominantly attributed to emissions controls and meteorological conditions (i.e., relative humidity $[\mathrm{RH}]$ and temperature).

\subsection{Carbonaceous fraction, water-soluble ions, and light absorption measurements}

The amounts of OC and EC were determined using an OC/EC analyzer (Cavalli et al., 2010). Filter punches were extracted with ultrapure water, and the water extracts were used to analyze water soluble ions. WSOC and light absorption methods have been described previously (Hecobian et al., 2010; Kirillova et al., 2014b). Details on the analytical methods for OC, EC, WSOC, HULIS, watersoluble ions $\left(\mathrm{F}^{-}, \mathrm{Cl}^{-}, \mathrm{NO}_{3}^{-}, \mathrm{SO}_{4}^{2-}, \mathrm{Na}^{+}, \mathrm{K}^{+}, \mathrm{NH}_{4}^{+}, \mathrm{Mg}^{2+}\right.$, and $\left.\mathrm{Ca}^{2+}\right)$, and light absorption (MAE and AAE) are provided in Appendix $\mathrm{S} 1$ and Appendix S2 in the Supporting Information.

\subsection{Carbon isotope analysis}

The samples selected for carbon isotopic analysis were the same as those used in an earlier study from the same campaign (Liu et al., 2016a). Briefly, 18 samples were selected for the carbon isotopic analysis. Six samples were selected to represent each period (before, during, and after APEC), and the samples from each period were pooled into separate daytime and nighttime samples. The selected sample filters were acidified in a desiccator over $12 \mathrm{M} \mathrm{HCl}$ for $24 \mathrm{~h}$ to remove carbonates and then dried at $60^{\circ} \mathrm{C}$ for $1 \mathrm{~h}$ (Kirillova et al., 2013). 
For the stable carbon measurements, WSOC and HULIS were isolated as described in Appendix S1. WSOC and HULIS were redissolved in ultrapure water, and $30-50 \mu \mathrm{g}$ of carbon was spiked into a tin cup washed with acetone under ultrasonication to remove organic contaminants. After evaporation in an oven at $60^{\circ} \mathrm{C}$, the tin cup containing the sample was crushed into a ball to measure the stable isotopic composition $\left(\delta^{13} \mathrm{C}\right)$ using a Finnigan MAT-252 mass spectrometer (Thermo Electron Corporation, Waltham, MA, USA), relative to that of a standard, Vienna Pee Dee Belemnite. Samples were analyzed at least three times, and the analytical error in the carbon isotope ratios was within $0.2 \%$ (relative standard deviation was less than $1 \%$ ).

For the radiocarbon measurements, more than $150 \mu \mathrm{g}$ of carbon from HULIS was combusted into $\mathrm{CO}_{2}$, cryogenically trapped, and reduced into graphite targets for ${ }^{14} \mathrm{C}$ determination at the National Electrostatics Corporation compact accelerator mass spectrometry facility at Peking University (Beijing, China) (Liu et al., 2013, 2014). The radiocarbon data were expressed as the fraction of modern carbon $\left(f_{\mathrm{m}}\right)$ and normalized to a $\delta^{13} \mathrm{C}$ of $-25 \%$. The $f_{\mathrm{m}}$ was converted into the fraction of non-fossil carbon $\left(f_{\text {nf }}\right)$ with a correction factor of $1.052 \pm 0.013$ based on the long-term time series of ${ }^{14} \mathrm{CO}_{2}$ at the background station (Levin and Kromer, 2004; Levin et al., $2013)$; thus, the $f_{\mathrm{nf}}$ was calculated as $f_{\mathrm{nf}}=f_{\mathrm{m}} / 1.052$. The $f_{\mathrm{nf}}$ can range from 0 (pure fossil carbon) to 1 (pure modern carbon) and directly reflects the relative fossil and non-fossil contribution to carbon. The $f_{\mathrm{m}}$ values were converted into $\Delta^{14} \mathrm{C}$ using the following equation:

$\Delta{ }^{14} \mathrm{C}_{\text {sample }}=1000 *\left[f_{\mathrm{m}} * \mathrm{e}^{(1 / 8267) *(1950-2015)}-1\right]$

The $f_{\mathrm{m}}$ values of WSOC and non-HULIS (non-HULIS $=$ WSOCHULIS) were obtained from an earlier study (Liu et al., 2016a) and isotope mass balance calculation, respectively. The uncertainty of $f_{\text {nf }}$ for HULIS was obtained from an error propagation, and included uncertainties in the HULIS concentration, variability of the reference $f_{\mathrm{m}}$, and measurement uncertainty of $f_{\mathrm{m}, \text { HuLIs. }}$

\subsection{Ultrahigh resolution ESI FT-ICR MS analysis of HULIS}

We used the same samples for the ESI FT-ICR MS analysis as those used for the carbon isotopic analysis, from October 25-27, November 5-7, and November 18-20, 2014, for the before, during, and after APEC periods, respectively. We disregarded diurnal variations and pooled the daytime and nighttime samples, with six samples per period. A filter punch $(4.5 \mathrm{~cm}$ in diameter, corresponding to $\sim 35 \mathrm{~m}^{3}$ of sampled air) was taken from every sample, and the six samples were combined and extracted with $100 \mathrm{~mL}$ of ultrapure water. The aqueous extracts were adjusted to $\mathrm{pH}=2$ by adding $\mathrm{HCl}$, and then passed through a solid-phase extraction cartridge (Oasis HLB, $30 \mu \mathrm{m}, 60 \mathrm{mg} /$ cartridge; Waters Corporation, Milford, MA, USA). The retained HULIS were eluted with $2 \%(\mathrm{v} / \mathrm{v})$ ammonia/methanol and evaporated until dry under a gentle nitrogen gas stream. Finally, the HULIS were redissolved in $1 \mathrm{~mL}$ of methanol before the ESI FT-ICR MS analysis. The HULIS were analyzed using a solariX XR FT-ICR MS (Bruker Daltonics GmbH, Bremen, Germany) equipped with a 9.4-T refrigerated actively shielded superconducting magnet (Bruker Biospin, Wissembourg, France) and a ParaCell analyzer cell (Gamry Instruments, Warminster, PA, USA). The samples were ionized in the negative ion mode using the ESI ion source (Bruker Daltonics). The detection mass range was set to $\mathrm{m} / \mathrm{z} 150-800$. The ion accumulation time was set to $0.6 \mathrm{~s}$. A total of 100 continuous $4 \mathrm{M}$ data points of FT-ICR transients were co-added to enhance the signal-to-noise ratio and dynamic range. Field blank filters were processed and analyzed following the same procedure to detect possible contamination.
The mass spectra were calibrated externally with arginine clusters in the negative ion mode using a linear calibration. The final spectrum was internally recalibrated with typical $\mathrm{O}_{6} \mathrm{~S}_{1}$ class species peaks using quadratic calibration in DataAnalysis ver. 4.4 software (Bruker Daltonics). A typical mass-resolving power $(\mathrm{m} / \Delta \mathrm{m} 50 \%$, in which $\Delta \mathrm{m} 50 \%$ is the magnitude of the mass spectral peak full width at half-maximum peak height $)>450,000$ at $\mathrm{m} / \mathrm{z} 319$ with $<0.2 \mathrm{ppm}$ absolute mass error was achieved. Further details on data processing are provided in Appendix S3.

\section{Results and discussion}

To investigate the impact of emissions controls on the sources, optical properties, and compositions of HULIS, we separated the study period into three periods: before (October 25-31), during (November 1-12), and after APEC (November 13-20, 2014).

\subsection{Concentrations and compositions of organic fractions}

Fig. 1 and Table S1 show the temporal variations in the concentrations and compositions of organic components. Over the whole study period, the HULIS-C concentration ranged from 0.38 to $11.0 \mu \mathrm{g} \mathrm{C} / \mathrm{m}^{3}$ (average: $3.79 \pm 3.03 \mu \mathrm{g} \mathrm{C} / \mathrm{m}^{3}$ ), comparable to that observed in Shanghai during winter (Qiao et al., 2015; Zhao et al., 2015a), but higher than that in the Pearl River Delta (PRD) region in southern China (Kuang et al., 2015; Lin et al., 2010). HULIS were significantly correlated with primary tracers (i.e., $\mathrm{K}^{+}$and EC) and secondary species (i.e., $\mathrm{SO}_{4}^{2-}, \mathrm{NO}_{3}^{-}, \mathrm{NH}_{4}^{+}$, and oxalate) during the study period (Fig. S1), indicating that primary emission (i.e., biomass burning and fossil fuel combustion) and secondary formation were both important sources of HULIS. According to the analysis of variance (ANOVA) test $(P<0.05$ is considered statistically significant), HULIS-C/OC ratios were higher before APEC than during and after APEC $(0.34 \pm 0.09,0.25 \pm 0.08$, and $0.26 \pm 0.04$, respectively). Because aqueous phase reactions are important formation pathways of HULIS (Chang and Thompson, 2010; Holmes and Petrucci, 2006), the secondary formation of HULIS was promoted under higher RH before APEC (Table S1). Meanwhile, air masses passed over the industrial regions south of Beijing (i.e., Henan and Hebei provinces) more frequently before APEC than during and after APEC (Fig. S2), carrying abundant precursors for secondary reactions. During the APEC summit, emissions sources were limited, and air masses mainly originated from the relatively clean areas north and northwest of Beijing, with better weather conditions for pollutant dilution (i.e., higher wind speed and lower $\mathrm{RH})$; therefore, HULIS-C concentrations were markedly lower and HULIS-C accounted for the largest fraction of the reduction in OC (52.2\%). After the control period, local primary OC (POC) emissions were expected to increase due to coal combustion for central heating. Indeed, the POC/OC ratios were higher after APEC than before and during APEC $(0.56 \pm 0.13,0.49 \pm 0.24$, and $0.66 \pm 0.17$, respectively). Because most POC emissions were WISOC (Miyazaki et al., 2006), the lower temperature and RH after APEC prevented the oxidization of WISOC into WSOC; therefore, WISOC was the largest contributor to the increase in OC (62.4\%). Moreover, consistent with the $\mathrm{POC} / \mathrm{OC}$ ratios, the WISOC/OC ratios were also higher after APEC than during the other two periods $(0.48 \pm 0.09$, $0.52 \pm 0.14$, and $0.57 \pm 0.08$, respectively). Additionally, the secondary formation of HULIS after APEC was expected to be lower than that before APEC, due to lower RH. Indeed, previous studies using organic tracers (i.e., dicarboxylic acids, keto-carboxylic acids, and $\alpha$-dicarbonyls) and aerosol mass spectrometry have also found that SOA production was suppressed after APEC (Wang et al., 2015, 2017). The lower abundances of secondary inorganic ions and lower WSOC/OC ratios further supported this expectation. However, the 


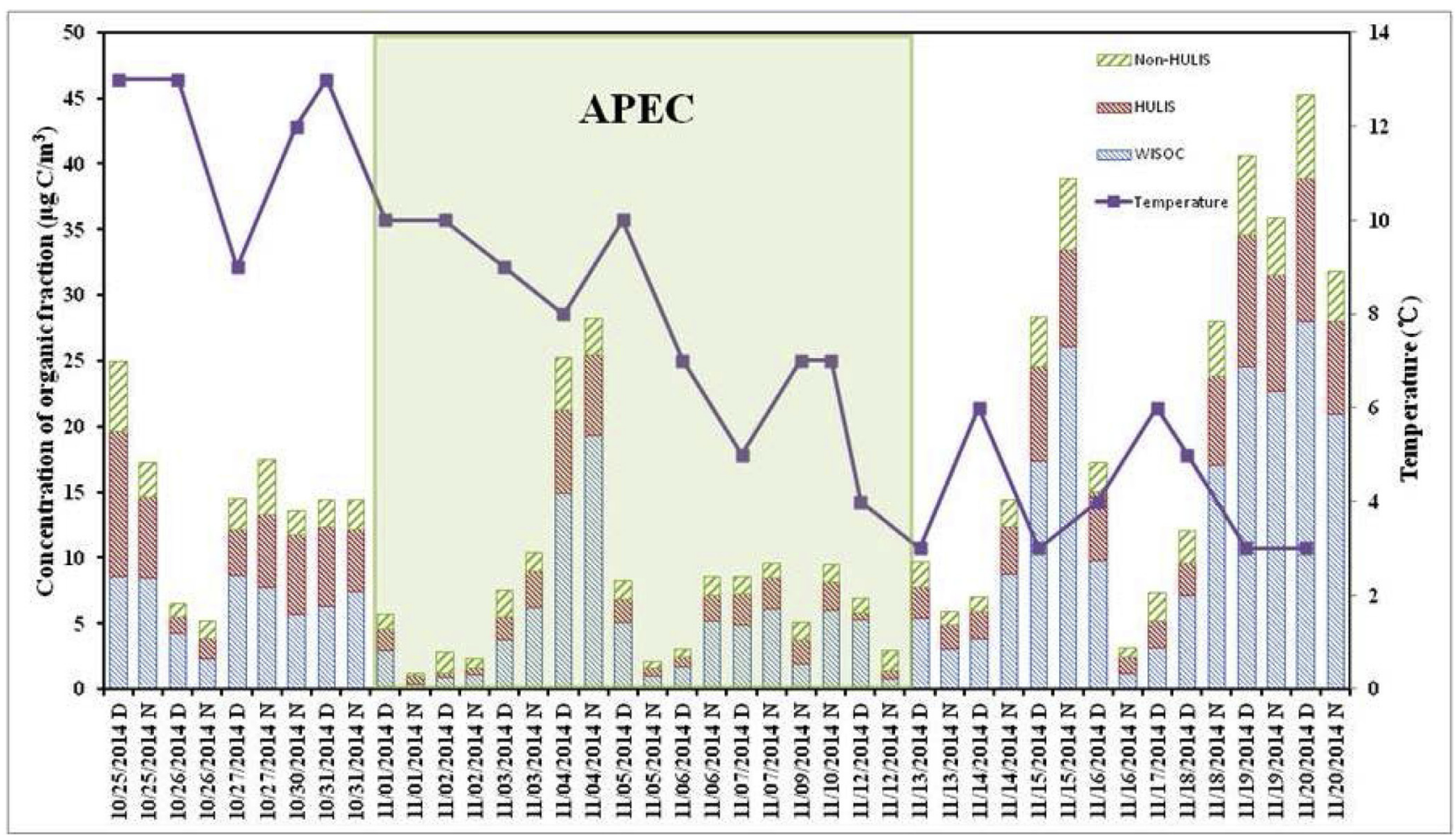

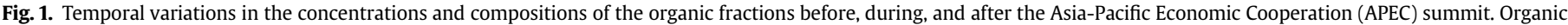
carbon $(O C)=$ water-soluble organic carbon (WSOC) + water-insoluble OC (WISOC), and WSOC $=$ humic-like substances (HULIS) + non-HULIS .

average concentration of HULIS after APEC was comparable to that before APEC, indicating that HULIS were mainly emitted from primary sources and were relatively fresh after APEC. Thus, the variations in the concentrations and compositions of the organic fractions may be related to the emissions controls and the meteorological conditions.

\subsection{Optical properties of HULIS}

Table S2 provides a comparison of the mass absorption efficiency (MAE) and Angstrom absorption exponent (AAE) values in this study with those from previous studies that used the solvent extraction method. The MAE 365 of WSOC during the whole study period $\left(0.35-1.75 \mathrm{~m}^{2} / \mathrm{g} \mathrm{C}\right.$, average: $1.05 \pm 0.32 \mathrm{~m}^{2} / \mathrm{g} \mathrm{C}$ ) was lower than those of previous reports in Beijing in the winter (Cheng et al., 2011; Du et al., 2014), which may have resulted from the emissions controls implemented during the APEC summit. Overall, the $\mathrm{MAE}_{365}$ of WSOC in this study was higher than those of most places worldwide, but lower than source regions in South Asia (i.e., Delhi and Patiala, India) (Kirillova et al., 2014b). The MAE 365 of HULIS $\left(0.71-2.00 \mathrm{~m}^{2} / \mathrm{g} \mathrm{C}\right.$, average: $\left.1.43 \pm 0.33 \mathrm{~m}^{2} / \mathrm{g} \mathrm{C}\right)$ was not only higher than that of WSOC $(P<0.05)$, but was comparable to that of bulk methanol extracts from Beijing and Los Angeles, United States, containing water-insoluble compounds with greater light absorption capacities. Moreover, HULIS accounted for $58.7 \pm 11.5 \%$ of WSOC, while contributing $80.2 \pm 6.1 \%$ of the absorption by WSOC (Fig. S3). Park and Yu (2016) also found that light absorption by WSOC from biomass burning had a stronger relationship with HULIS than with non-HULIS. Thus, HULIS are the main lightabsorbing components of WSOC. Non-HULIS are the components with the highest degree of oxidation within organic fractions (Chen et al., 2016a, 2016b), and the relatively weak light absorption capacity of non-HULIS may be due to the fact that chromophores in organic materials tend to bleach during the oxidation process, which is supported by chamber experiments and field observations showing that the light absorption of $\mathrm{BrC}$ decreases with aging time (Liu et al., 2016b; Saleh et al., 2013; Srinivas et al., 2016).

The AAE values of HULIS ranged from 2.96 to 5.94 (average: $4.66 \pm 0.83$ ), lower than those of WSOC (3.43-6.76, average: $5.27 \pm 0.81, P<0.05)$, indicating that HULIS have a higher degree of conjugation. AAE values vary widely in different locations worldwide. They appear to be related to sources, atmospheric processes (Li et al., 2016), fitting wavelength ranges, OC polarity (Chen et al., 2016b), and extraction methods (Zhang et al., 2013). However, in this study we found that the $\mathrm{pH}$ of water extracts correlated well with the AAE values of HULIS and WSOC (Fig. S4a). This may be associated with the proton dissociation of the acidic functional groups of $\mathrm{BrC}$ species at higher $\mathrm{pH}$, which would cause the absorption spectra of some $\mathrm{BrC}$ species to shift to longer wavelengths upon deprotonation (Mo et al., 2017; Phillips et al., 2017). Therefore, care should be taken when using AAE values to determine $\mathrm{BrC}$ absorption.

In all samples, the $\mathrm{MAE}_{365}$ of HULIS before APEC was $1.21 \pm 0.28 \mathrm{~m}^{2} / \mathrm{g} \mathrm{C}$, comparable to that during APEC $\left(1.34 \pm 0.29 \mathrm{~m}^{2} /\right.$ g C, $P=0.38$ ) (Fig. S5). However, the MAE 365 of HULIS increased by $25 \%$ to $1.68 \pm 0.23 \mathrm{~m}^{2} / \mathrm{g} \mathrm{C}$ after APEC. A similar pattern was observed for the MAE 365 of WSOC $(0.97 \pm 0.15,0.86 \pm 0.29$, and $1.31 \pm 0.24 \mathrm{~m}^{2} / \mathrm{g}$ C for the before, during, and after APEC periods, respectively). The significantly higher $M E_{365}$ values after APEC may have been related to the sources, compositions, and atmospheric processes of HULIS, as discussed below.

\subsection{Source appointment and atmospheric processing of HULIS with carbon isotopes}

Table 1 summarizes the carbon isotopic signatures $\left(\delta^{13} \mathrm{C}\right.$ and 
Table 1

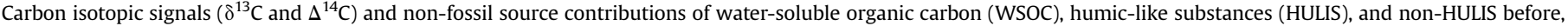
during, and after the Asia-Pacific Economic Cooperation (APEC) summit.

\begin{tabular}{|c|c|c|c|c|c|c|c|c|c|c|}
\hline \multirow[t]{2}{*}{ Period } & & \multicolumn{3}{|l|}{ WSOC } & \multicolumn{3}{|l|}{ HULIS } & \multicolumn{3}{|c|}{ Non-HULIS ${ }^{\mathrm{b}}$} \\
\hline & & $\Delta^{14} C^{\mathrm{a}}(\% 0)$ & $\delta^{13} \mathrm{C}(\% 0)$ & $f_{\text {non-fossil }}{ }^{\mathrm{a}}(\%)$ & $\Delta^{14} \mathrm{C}(\% 0)$ & $\delta^{13} \mathrm{C}(\% 0)$ & $f_{\text {non-fossil }}(\%)$ & $\Delta^{14} \mathrm{C}(\% 0)$ & $\delta^{13} \mathrm{C}(\% 0)$ & $f_{\text {non-fossil }}(\%)$ \\
\hline \multirow[t]{3}{*}{ Before APEC } & Daytime & -460 & -22.8 & $52 \pm 6$ & -484 & -23.8 & $49 \pm 3$ & -418 & -20.9 & $56 \pm 7$ \\
\hline & Nighttime & -444 & -22.5 & $53 \pm 6$ & -423 & -23.4 & $55 \pm 3$ & -478 & -21.0 & $50 \pm 7$ \\
\hline & Mean & $-452 \pm 11$ & $-22.6 \pm 0.2$ & $53 \pm 1$ & $-453 \pm 43$ & $-23.6 \pm 0.3$ & $52 \pm 4$ & $-448 \pm 42$ & $-20.9 \pm 0.1$ & $53 \pm 4$ \\
\hline \multirow[t]{3}{*}{ During APEC } & Daytime & -350 & -23.3 & $62 \pm 7$ & -434 & -25.2 & $54 \pm 3$ & -233 & -20.8 & $73 \pm 9$ \\
\hline & Nighttime & -345 & -23.3 & $63 \pm 7$ & -379 & -24.9 & $59 \pm 3$ & -292 & -21.0 & $68 \pm 9$ \\
\hline & Mean & $-347 \pm 4$ & $-23.3 \pm 0.0$ & $63 \pm 1$ & $-406 \pm 39$ & $-25.0 \pm 0.2$ & $57 \pm 4$ & $-263 \pm 42$ & $-20.9 \pm 0.1$ & $71 \pm 4$ \\
\hline \multirow[t]{4}{*}{ After APEC } & Daytime & -443 & -22.8 & $53 \pm 6$ & -479 & -24.1 & $50 \pm 3$ & -387 & -20.8 & $58 \pm 8$ \\
\hline & Nighttime & -416 & -22.7 & $56 \pm 7$ & -462 & -24.1 & $52 \pm 3$ & -332 & -20.3 & $64 \pm 8$ \\
\hline & Mean & $-430 \pm 20$ & $-22.8 \pm 0.1$ & $55 \pm 2$ & $-470 \pm 13$ & $-24.1 \pm 0.0$ & $51 \pm 1$ & $-360 \pm 39$ & $-20.5 \pm 0.4$ & $61 \pm 4$ \\
\hline & Overall mean & $-410 \pm 50$ & $-22.9 \pm 0.3$ & $57 \pm 5$ & $-443 \pm 40$ & $-24.2 \pm 0.6$ & $53 \pm 4$ & $-357 \pm 89$ & $-20.8 \pm 0.3$ & $62 \pm 8$ \\
\hline
\end{tabular}

${ }^{\mathrm{a}}$ The $\Delta^{14} \mathrm{C}$ and $f_{\text {non-fossil }}$ values of WSOC were obtained from an earlier study (Liu et al., 2016a).

b All values for non-HULIS were calculated from the mass balance based on the measured WSOC and HULIS.

$\Delta^{14} \mathrm{C}$ ) and non-fossil fractions of WSOC, HULIS, and non-HULIS. The average contribution of non-fossil sources to HULIS was $53 \pm 4 \%$, which accounted for 33\% of WSOC (Fig. S6). The non-fossil fraction of HULIS was comparable to that of Guangzhou, South China (58\%) (Song et al., 2012). The non-fossil contribution to HULIS was higher at night ( $55 \pm 3 \%$ ), especially during APEC, indicating more biomass burning activities at night, which was further supported by the higher $\mathrm{K}^{+}$levels during the nighttime than in the daytime $\left(0.35 \pm 0.17\right.$ vs. $\left.0.91 \pm 0.73 \mu \mathrm{g} / \mathrm{m}^{3}, P<0.05\right)$. The higher concentrations of $\mathrm{K}^{+}$at night may also be due to the lower boundary layer and stable meteorological conditions, but Xu et al. (2015), using aerosol mass spectrometry, also found that organic aerosols from biomass burning were increased at night compared to the day. Therefore, the higher non-fossil contribution of HULIS in the nighttime may be attributed to biomass burning. Compared to those before APEC, fossil HULIS and non-fossil HULIS were reduced by $70 \%$ and $63 \%$ during the APEC period, while the corresponding values for nonHULIS were $76 \%$ and $48 \%$, respectively. Given the fact that biogenic VOCs emissions are low during the winter in Beijing (Wang et al., 2003), this result indicates that control strength of non-fossil sources, especially biomass burning, was not as well as fossil sources. Similar results have been observed in other studies using different technologies (Wang et al., 2015; Xu et al., 2015). ${ }^{14} \mathrm{C}$ enrichment in WSOC has been observed worldwide (Bosch et al., 2014; Kirillova et al., 2013, 2014b; Liu et al., 2014), and our results showed that ${ }^{14} \mathrm{C}$ in WSOC was relatively more enriched in nonHULIS than in HULIS, consistent with a study that observed larger influences of fossil sources on the hydrophobic fraction of dissolved OC in rainwater (Avery et al., 2013). In our previous study, the $\Delta^{14} \mathrm{C}$ signal showed that non-HULIS had a larger non-fossil contribution $(62 \pm 8 \%)$ than the other carbonaceous components (WSOC: $57 \pm 4 \%$, WISOC: $54 \pm 7 \%$, EC: $38 \pm 7 \%$ ) (Liu et al., 2016a), and nonfossil non-HULIS accounted for $24 \%$ of WSOC. This indicates that non-HULIS were greatly affected by biomass burning and secondary formation from biogenic precursors.

In addition to radiocarbon, stable carbon isotopic signatures can be used to further examine the sources and atmospheric processing of OA. In SOA formation processes, ${ }^{13} \mathrm{C}$ depletion occurs because organic compounds depleted in ${ }^{13} \mathrm{C}$ have faster reaction rates (Rudolph et al., 2000). In contrast, when high molecular weight compounds react with oxidants (i.e., hydroxyl radicals and ozone), the high molecular compounds with lighter isotopes react faster and release ${ }^{12} \mathrm{C}$-enriched volatile compounds or $\mathrm{CO} / \mathrm{CO}_{2}$, and the remaining substrate is consequently enriched in ${ }^{13} \mathrm{C}$ due to kinetic isotope effects (Aggarwal and Kawamura, 2008; Kirillova et al., 2014a; Wang and Kawamura, 2006). These two opposing processes have been evidenced in laboratory experiments and field observations (Aggarwal and Kawamura, 2008; Kirillova et al., 2014a; Pavuluri and Kawamura, 2016; Wang and Kawamura, 2006). The stable carbon signature $\left(\delta^{13} \mathrm{C}\right)$ can also provide more information for source appointment, because the $\delta^{13} \mathrm{C}$ of C4 plants $(-17$ to $-9 \%$ ) and coal $(-23$ to $-21 \%$ ) are higher than those of $\mathrm{C} 3$ plants ( -34 to $-25 \%$ ) and liquid fossil fuel $(-28$ to $-25 \%$ ) (Table S7). The average $\delta^{13} \mathrm{C}$ value of HULIS was $-24.2 \pm 0.6 \%$, which was within the range of liquid fossil fuel and C3 plants (Ancelet et al., 2013; Dai et al., 2015; Wang et al., 2013). Although the difference in $\delta^{13} \mathrm{C}$-HULIS was small throughout the study period, we found that the level of $\delta^{13} \mathrm{C}$-HULIS was slightly higher before and after APEC, which may have been due to different factors. For example, the higher RH may have facilitated the aqueous phase processes to form more oxidized HULIS before APEC (Ervens et al., 2011), which is consistent with aerosol mass spectrometer (AMS) results showing that the $\mathrm{OA}$ had a higher $\mathrm{O} / \mathrm{C}$ ratio in the same period (Xu et al., 2015). However, the high $\delta^{13} \mathrm{C}$-HULIS values after APEC may have been affected by coal combustion for central heating or C4 plant combustion, which is expected to be more highly enriched in ${ }^{13} \mathrm{C}$ (Andersson et al., 2015; Cao et al., 2011). Additionally, HULIS were not only slightly enriched in ${ }^{13} \mathrm{C}$ at night, but also had higher non-fossil contributions, as discussed above, indicating that $\mathrm{C} 4$ plant combustion was more prevalent at night. Non-HULIS were substantially enriched in ${ }^{13} \mathrm{C}(-20.8 \pm 0.3 \%$, $P<0.05)$ compared with HULIS, indicating that this fraction underwent more aging processes and oxidation, consistent with a study that reported that non-HULIS had the highest oxygen/carbon (O/C) ratio among the organic fractions (Chen et al., 2016a, 2016b). Another possibility is that $\mathrm{C} 4$ plant combustion preferentially produced non-HULIS. By combining the $\delta^{13} \mathrm{C}$ and $\Delta^{14} \mathrm{C}$ signals, we found that HULIS were more fossilized and more depleted in ${ }^{13} \mathrm{C}$ than non-HULIS (Fig. 2). Therefore, we deduced that fossil-derived OC has a slower aging rate than contemporary OC.

\subsection{Elemental composition of HULIS}

A total of 4032, 4672, and 4353 formulas were identified in the before, during, and after APEC samples, respectively (Table 2). The identified elemental formulas fell into four main compound classes: $\mathrm{CHO}, \mathrm{CHON}, \mathrm{CHOS}$, and CHONS compounds. More than $98 \%$ of sulfur (S)-containing compounds (CHOS + CHONS) in each sample had $\mathrm{O} / \mathrm{S}$ ratios $\geq 4$ for $\mathrm{CHOS}$ compounds, $\geq 7$ for $\mathrm{CHON}_{1} \mathrm{~S}$ compounds, and $\geq 10$ for $\mathrm{CHON}_{2} \mathrm{~S}$ compounds, supporting the assignment of a sulfate group $\left(-\mathrm{OSO}_{3} \mathrm{H}\right)$ for $\mathrm{CHOS}$ compounds and an additional one or two nitrooxy groups $\left(-\mathrm{ONO}_{2}\right)$ for CHONS compounds. Thus, the majority of the S-containing compounds in the samples were probably organosulfates and nitrooxy- 


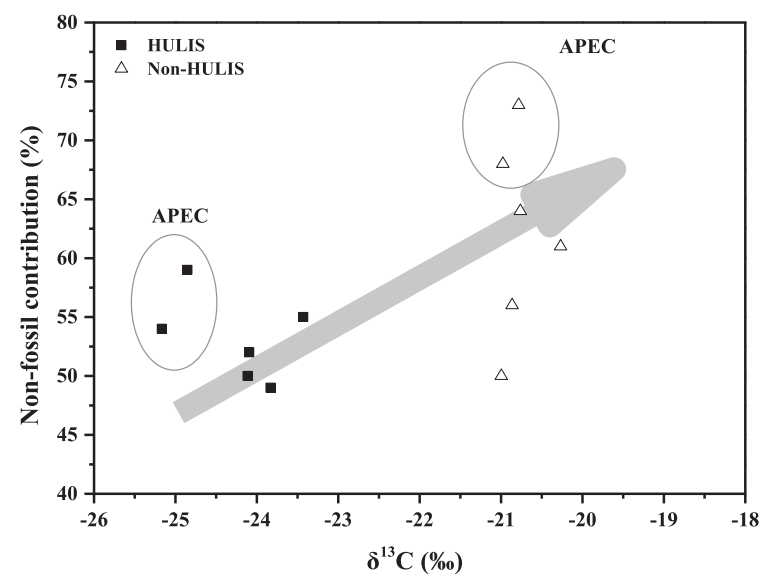

Fig. 2. Non-fossil contribution and $\delta^{13} \mathrm{C}$ of HULIS and non-HULIS in fine particulate matter $\left(\mathrm{PM}_{2.5}\right)$ before, during, and after the APEC summit. Six representative samples from each period (before, during, and after APEC) were pooled into separate daytime and nighttime samples, so that there are two isotopic data points for each period. The circles indicate the samples collected during APEC.

organosulfates. The MW and degrees of oxidation of these compounds were higher than those of non-S compounds (CHO and CHON), but the DBE values were lower (Table 2). However, it should be noted that the DBE values of CHOS and CHONS compounds were significantly higher than those in Shanghai (Tao et al., 2014) and the PRD region (Lin et al., 2012), and up to $59.4 \%$ of CHOS and $52.2 \%$ of CHONS formulas had DBE values $\geq 4$ and $\geq 5$, respectively (Fig. S7). This means that, in addition to biogenic VOCs (Surratt et al., 2008) and long-chain alkane-derived organosulfates (Tao et al., 2014), organosulfate formation from aromatic precursors may be important in Beijing (Jiang et al., 2016). In total, 98\% of CHON compounds had $\mathrm{O} / \mathrm{N}$ ratios $\geq 2$ (average: $5.82 \pm 2.56$ ), allowing for the assignment of at least one nitro $\left(-\mathrm{NO}_{2}\right)$ or nitrooxy $\left(-\mathrm{ONO}_{2}\right)$ group and other oxygen-containing groups (i.e., $-\mathrm{OH}$ and $-\mathrm{COOH}$ ). Additionally, assuming that compounds with a DBE $\geq 4$ (DBE $\geq 5$ for nitrogen-containing compounds, nitrooxy, or nitro groups containing a double bond) were aromatic, $>86 \%$ of these compounds had DBE values $\geq 5$ (Fig. S7), making organonitrates and nitroaromatic compounds major candidate compounds. However, if we use the aromaticity index (AI) to estimate the degree of molecular saturation (Koch and Dittmar, 2006), far fewer compounds contain aromatic structures. The non-S compounds were dominated by olefinic formulas, whereas most S-containing compounds were aliphatic (Figs. S9 and S10), and less than 5\% of them were aromatic. It should be noted that the $\mathrm{AI}$ is the more conservative

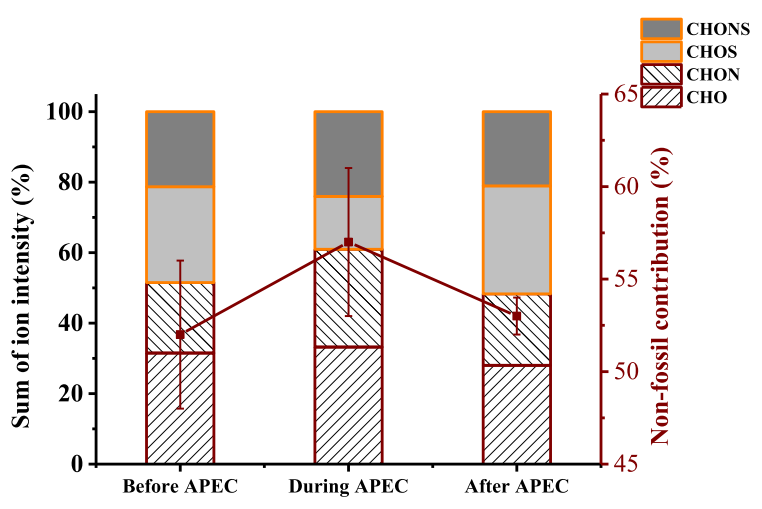

Fig. 3. Relative intensity fraction of each compound class and non-fossil contribution of HULIS before, during, and after the APEC summit. Six representative samples from each period (before, during, and after APEC) were pooled into separate daytime and nighttime samples for radiocarbon analysis. The diurnal variations were not considered in Fourier-transform ion cyclotron resonance mass spectrometry (FT-ICR MS) analyses.

criterion, and the AI may be underestimated if compounds contain more oxygen atoms. For example, the S-containing compounds with an aromatic ring have negative AI values (Table S5), mostly due to the presence of oxygen-containing functional groups. Thus, the molecular formulas may be more aromatic than indicated if $\mathrm{AI}$ is used. CHO compounds may contain organic acids (Lin et al., 2012), oxygenated polycyclic aromatic hydrocarbons (Lin et al., 2016), and oligomers formed via esterification (Mazzoleni et al., 2010), which tend to ionize in the ESI-negative mode due to the presence of carbonyl, carboxyl, and hydroxyl functional groups.

Throughout the study period, non-S compounds were more abundant than S-containing ones (Fig. S11). However, we found that the fraction of S-containing compounds was higher before and after APEC, whereas that of CHON compounds was higher during APEC (Fig. 3). Combined with the ${ }^{14} \mathrm{C}$ data shown in Fig. 3 , we found that the S-containing compounds were associated with fossil fuel combustion, and large amounts of sulfur dioxide emitted from fossil fuel combustion before and after APEC may have facilitated the conversion of organic compounds into organosulfates. However, a higher fraction of $\mathrm{CHON}$ compounds was observed during APEC. After comparing the CHON compound formulas, 1017 formulas were detected in all periods, and 489 formulas were detected only during APEC. Compared to those detected in both periods, the formulas only detected during APEC typically had higher MW, which accounted for $14.2 \%$ of the CHON intensity during APEC (Fig. S12). CHON compounds arise not only

Table 2

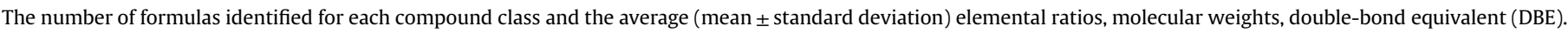

\begin{tabular}{|c|c|c|c|c|c|c|}
\hline Period & Elemental composition & Number of formulas & Molecular weight (Da) & $\mathrm{H} / \mathrm{C}$ & $\mathrm{O} / \mathrm{C}$ & DBE \\
\hline \multirow[t]{5}{*}{ Before APEC } & $\mathrm{CHO}$ & 1274 & $337.81 \pm 83.73$ & $1.26 \pm 0.38$ & $0.38 \pm 0.17$ & $6.86 \pm 3.44$ \\
\hline & CHON & 1416 & $350.91 \pm 76.84$ & $1.13 \pm 0.32$ & $0.45 \pm 0.15$ & $8.21 \pm 3.07$ \\
\hline & CHOS & 677 & $355.01 \pm 75.54$ & $1.54 \pm 0.35$ & $0.54 \pm 0.21$ & $3.87 \pm 2.73$ \\
\hline & CHONS & 665 & $399.37 \pm 72.80$ & $1.67 \pm 0.34$ & $0.75 \pm 0.28$ & $3.38 \pm 2.16$ \\
\hline & Overall & 4032 & $355.43 \pm 80.87$ & $1.33 \pm 0.40$ & $0.50 \pm 0.23$ & $6.26 \pm 3.58$ \\
\hline \multirow[t]{5}{*}{ During APEC } & $\mathrm{CHO}$ & 1482 & $347.45 \pm 86.79$ & $1.22 \pm 0.40$ & $0.36 \pm 0.16$ & $7.63 \pm 4.08$ \\
\hline & CHON & 1977 & $365.48 \pm 83.75$ & $1.17 \pm 0.34$ & $0.42 \pm 0.16$ & $8.50 \pm 3.82$ \\
\hline & CHOS & 589 & $343.01 \pm 76.27$ & $1.52 \pm 0.37$ & $0.51 \pm 0.19$ & $4.01 \pm 2.99$ \\
\hline & CHONS & 624 & $402.31 \pm 77.10$ & $1.65 \pm 0.34$ & $0.73 \pm 0.29$ & $3.62 \pm 2.50$ \\
\hline & Overall & 4672 & $361.84 \pm 84.94$ & $1.29 \pm 0.40$ & $0.46 \pm 0.22$ & $7.01 \pm 4.14$ \\
\hline \multirow[t]{5}{*}{ After APEC } & $\mathrm{CHO}$ & 1367 & $345.34 \pm 84.64$ & $1.10 \pm 0.39$ & $0.35 \pm 0.14$ & $8.99 \pm 4.54$ \\
\hline & CHON & 1370 & $353.51 \pm 78.63$ & $1.02 \pm 0.40$ & $0.41 \pm 0.13$ & $9.64 \pm 3.51$ \\
\hline & CHOS & 841 & $360.21 \pm 71.54$ & $1.46 \pm 0.40$ & $0.47 \pm 0.18$ & $4.77 \pm 3.25$ \\
\hline & CHONS & 775 & $394.09 \pm 75.04$ & $1.46 \pm 0.38$ & $0.64 \pm 0.25$ & $5.09 \pm 2.99$ \\
\hline & Overall & 4353 & $359.45 \pm 80.44$ & $1.21 \pm 0.41$ & $0.44 \pm 0.20$ & $7.69 \pm 4.31$ \\
\hline
\end{tabular}


due to primary emission from biomass burning and sea spray aerosol (Laskin et al., 2009; Smith et al., 2009; Wozniak et al., 2014), but also secondary formation via various mechanisms (Harrison et al., 2005; Ng et al., 2017). Because Beijing was less affected by marine sources, the higher contribution of $\mathrm{CHON}$ compounds was likely related to the higher contribution of nonfossil sources during APEC, especially biomass burning. However, a previous study showed that the reduction of NO was greater than that of $\mathrm{NO}_{2}$ in the surrounding area during APEC (Wang et al., 2015), which may have facilitated the formation of nitrate radicals. Considering that the reactions of nitrate radicals with organic compounds produce a high yield of organonitrates (Rollins et al., 2012), the higher fraction of CHON compounds during APEC may also have been due to the influence of nitrate radical chemistry. Additionally, the aromatic fraction in each compound class was higher after APEC than during APEC, which may be attributable to the higher fossil fuel contribution of HULIS (Figs. S7 and S8). Although the fossil fuel contribution of HULIS before APEC was similar to that after APEC, the aromatic fractions in each compound class were lower before APEC, mainly due to the enhanced photochemical aging of HULIS under higher temperature and $\mathrm{RH}$ conditions and the destruction of aromatic structures during the oxidation process. This was supported by the higher $\mathrm{O} /$ $C$ ratio of HULIS before APEC $(0.50 \pm 0.23)$ than after APEC $(0.44 \pm 0.20)$, indicating that the HULIS after APEC were relatively fresh, and explaining the difference in the ${ }^{13} \mathrm{C}$ enrichment before and after APEC, as discussed in the previous section.

As shown in Fig. S13a, the majority of CHO compounds were in the range from $C_{10}$ to $C_{25}$, with much higher relative abundances before APEC. These relatively high molecular weight compounds may be oligomers, and the much higher relative abundances before APEC may reflect higher biogenic VOCs emissions (e.g., isoprene and monoterpenes) due to higher temperatures promoting the formation of high MW compounds (Kundu et al., 2012; Li et al., 2015). However, this does not exclude the effects of aqueous phase processes. For example, phenols (e.g., guaiacol and syringol) are commonly emitted from biomass burning. Although the $\mathrm{K}^{+}$levels $(P=0.457)$ and nonfossil fuel contributions were comparable before and after APEC, the relative intensity of phenol oligomers (i.e., $\mathrm{C}_{18} \mathrm{H}_{14} \mathrm{O}_{3}$, $\mathrm{C}_{16} \mathrm{H}_{18} \mathrm{O}_{6}$, and $\mathrm{C}_{14} \mathrm{H}_{14} \mathrm{O}_{4}$ ) was higher before APEC (Table S4), which may reflect the fact that higher RH can promote the production of oligomers in aqueous phase processes. The relative intensity of hydroxylated phenol oligomers (i.e., $\mathrm{C}_{18} \mathrm{H}_{14} \mathrm{O}_{4-8}$, $\mathrm{C}_{16} \mathrm{H}_{18} \mathrm{O}_{7-10}$, and $\mathrm{C}_{14} \mathrm{H}_{14} \mathrm{O}_{5-10}$ ) usually increased with their degree of hydroxylation, but these increases were relatively higher before APEC. Moreover, the $\mathrm{CHO}$ compounds with higher oxygen numbers $(0>6)$ were more abundant before APEC compared with the other two periods (Fig. S13b), indicating that the formation of highly oxidized compounds is promoted in aqueous processes. This is consistent with the fact that compounds formed from aqueous processes usually have a higher $\mathrm{O} / \mathrm{C}$ ratios (Ervens et al., 2011; Yu et al., 2016). For the S-containing compounds, we found that the compounds formed from 2methylnaphthalene and naphthalene had lower relative intensity during APEC relative to the other two periods (Table S5), reflecting the emissions control measures during APEC. However, as listed in Table S5, organosulfates were generated from biogenic precursors with higher relative intensity, despite the fact that biogenic VOCs emissions were lower after APEC. In fact, S-containing compounds were more abundant after APEC (Fig. S13c). By comparing the molar cation/anion ratio, we found that the particles were more acidic after APEC than before APEC $(1.09 \pm 0.19$ vs. $1.34 \pm 0.37, P<0.05)$, implying that acid-catalyzed formation of organosulfates may have promoted the relatively higher particle acidity after APEC (Riva et al., 2015; Surratt et al., 2008).

\subsection{Factors affecting the light absorption capacity of HULIS}

Because HULIS are important components of $\mathrm{BrC}$, understanding the factors affecting the light absorption capacity of HULIS is critical for assessing the evolution of the optical properties of $\mathrm{BrC}$. To investigate the factors responsible for variations in the $\mathrm{MEA}_{365}$ of HULIS, we must further discuss the samples selected for the radiocarbon and high-resolution mass spectrum analyses. Although the $\mathrm{pH}$ of water extracts can affect the AAE, there was no significant relationship between the $\mathrm{MAE}_{365}$ and liquid $\mathrm{pH}$ (Fig. S4b). Therefore, we can exclude the effects of liquid $\mathrm{pH}$. However, pH can alter the light absorption capacity of specific compounds. Although the relationship between $\mathrm{MAE}_{365}$ and the liquid $\mathrm{pH}$ was weak in this study, it should be noted that the light absorption of water extracts is the sum of many light-absorbing compounds, and the response of the light absorption capacity to $\mathrm{pH}$ varies markedly among compounds. For example, Hinrichs et al. (2016) reported that 2,4-dinitrophenol in a pH 5.5 solution absorbed 3.3 times more solar power relative to that in a $\mathrm{pH} 3.5$ solution. Therefore, we cannot exclude the effects of $\mathrm{pH}$ on the light absorption capacity of specific compounds.

Sources have an important role in the light absorption capacity of BrC. The MAE 365 values of WSOC in Los Angeles were 4-6 times higher than those in Atlanta, United States, mainly because WSOC was dominated by fossil fuel sources in Los Angeles (Zhang et al., 2011). Chamber studies have shown that SOA formed from anthropogenic precursors (i.e., trimethylbenzene and toluene) under high- $\mathrm{NO}_{\mathrm{x}}$ conditions exhibited greater light absorption capacities than SOA produced from biogenic precursors (i.e., $\alpha$-pinene) under similar experimental conditions (Liu et al., 2016b; Nakayama et al., 2010). This may explain why higher $\mathrm{MAE}_{365}$ values of WSOC have been observed during the winter than the summer in Beijing and the United States, because emissions from anthropogenic precursors are much higher in winter (Cheng et al., 2011; Du et al., 2014; Hecobian et al., 2010). In this study, HULIS after APEC exhibited greater light absorption capacities relative to HULIS during APEC, likely due to their higher fossil contribution. However, the fossil contributions of HULIS before and after APEC were similar, but the $\mathrm{MAE}_{365}$ was much higher after APEC. Moreover, the fossil contribution of HULIS before APEC was higher than that during APEC, but the MAE 365 values before and during APEC were similar (Fig. 4). Therefore, light absorption capacity does not appear to be affected by source alone, and other factors may work together.

Atmospheric aging has a significant effect on the light

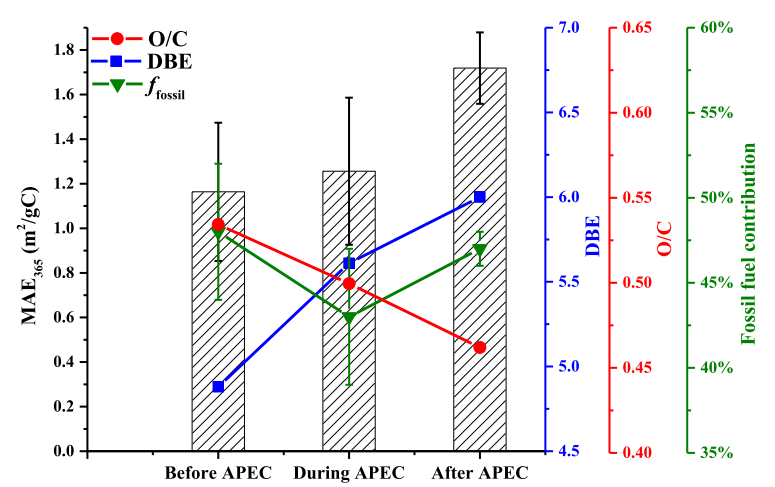

Fig. 4. Variations in the mass absorption efficiency $\left(\mathrm{MAE}_{365}\right)$, DBE, and $\mathrm{O} / \mathrm{C}$ based on the relative intensity of ions, and the fossil contribution of HULIS before, during, and after the APEC summit. 
absorption capacity of BrC (Lambe et al., 2013; Lee et al., 2014), but the mechanism involved is complex. The response of the light $a b-$ sorption capacity of different types of $\mathrm{BrC}$ to aging is highly variable, and an enhancement or reduction in the light absorption capacity of $\mathrm{BrC}$ is possible. In general, atmospheric aging of $\mathrm{OA}$ is accompanied by an increase in the $\mathrm{O} / \mathrm{C}$ ratio. Enhanced light absorption of $\mathrm{OA}$ with increasing $\mathrm{O} / \mathrm{C}$ ratio was observed in a chamber study (Lambe et al., 2013). In contrast, photolysis-driven aging may lead to the photobleaching of $\mathrm{BrC}$ (Lee et al., 2014; Liu et al., 2016b; Saleh et al., 2014), but the evolution of the optical properties of specific light-absorbing compounds can differ drastically. For example, the photobleaching rates of aged limonene/ozone SOA were much higher than that of naphthalene SOA in the same aging processes (Lee et al., 2014), and nitrophenols exhibited enhanced absorption at wavelengths $>400 \mathrm{~nm}$ during the initial stages, whereas rapid photobleaching occurred after longer photolysis (Zhao et al., 2015b). The MAE 365 values of HULIS decreased with increasing intensity-weighted average $\mathrm{O} / \mathrm{C}$ ratios, but increased with increasing DBE values (Fig. 4). Considering the arithmetic average of all formulas, the $\mathrm{O} / \mathrm{C}$ ratios and DBE values also exhibited opposite variation trends (Fig. S14). DBE can reflect the degree of unsaturation of a compound. The DBE values decreased with increasing $\mathrm{O} / \mathrm{C}$ ratios, indicating that unsaturated structures were preferentially destroyed during the oxidation process, thereby reducing the light absorption capacity of HULIS. Thus, the unsaturation level of HULIS plays an important role in their light absorption capacity.

MW may be related to the light absorption capacity of BrC. One modeling study showed that highly absorbent compounds likely have high MW (Sun et al., 2007), whereas Di Lorenzo and Young (2016) used size exclusion chromatography coupled with a visible UV detector and found that most BrC absorption arose from high MW components. In this study, the MW was determined using mass spectrometry, but we observed no significant differences in the average MW over the entire study period. However, we found that the degree of unsaturation tended to increase with increasing MW; thus, it seems that the relatively higher light absorption from high MW compounds was due to their high degree of unsaturation (Table S6). Based on the van Krevelen diagram for each compound class (Figs. S15-S17), most unsaturated compounds with DBEs $\geq 10$ (orange circles) were in the lower left area of the diagrams with both low $\mathrm{H} / \mathrm{C}$ and low $\mathrm{O} / \mathrm{C}$ ratios. These compounds not only had higher average DBE values, but also higher MW (Table S3) than the overall average values shown in Table 2. Although we do not know the relative absorption of these high MW compounds, they were shown to have relatively higher light absorption and were longlived in atmospheric aerosols, indicating that these species are more likely to have long-term effects on climate (Di et al., 2017; Jps et al., 2017).

In summary, the degree of unsaturation of HULIS appears to play an important role in their absorption capacity, which is affected by their sources and atmospheric aging processes. HULIS derived from fossil sources may have a relatively higher degree of unsaturation, with correspondingly higher light absorption capacities. However, the degree of unsaturation of HULIS with the same fossil contribution may differ due to different levels of aging (oxidation). Overall, we found that: (1) although the fossil contribution of HULIS before APEC was comparable to that after APEC, the unsaturation degree decreased during the oxidation processes such that the corresponding $\mathrm{MAE}_{365}$ values were lower before APEC; and (2) significantly higher $\mathrm{MAE}_{365}$ values were observed after APEC, not only because of the higher fossil contribution from coal combustion for central heating, but also because of the lower degree of oxidation, which led to a higher degree of unsaturation in HULIS after APEC.
$\mathrm{BrC}$ is attracting increasing global attention due to its lightabsorbing properties and warming effects. Light absorption capacity evolves in the atmosphere, but the underlying mechanisms are largely unknown. Previous laboratory experiments and field observations have shown that the absorption properties of $\mathrm{BrC}$ are strongly affected by their sources (Du et al., 2014; Zhang et al., 2011), atmospheric aging processes (Lambe et al., 2013; Lee et al., 2014; Zhong and Jang, 2014), combustion conditions (Chen and Bond, 2010; Saleh et al., 2014), and MW (Di Lorenzo and Young, 2016). However, laboratory studies have only considered $\mathrm{BrC}$ from limited precursors and cannot represent real atmospheric conditions, whereas field observations generally yield the effects of a single factor (i.e., sources, aging, or composition) on light absorption capacity. HULIS are an important component of $\mathrm{BrC}$, and elucidating the relationships among composition, oxidation processes, and sources may increase understanding of the evolution of $\mathrm{BrC}$ absorption. In this study, the short-term emissions reduction measures enacted during APEC provided a unique opportunity to study the responses of the light absorption properties of HULIS to their sources in ambient aerosol. Furthermore, to our knowledge, this is the first study to combine dual carbon isotopic analysis and FT-ICR MS to investigate the effects of composition, sources, and oxidation levels on the light-absorbing capacity of HULIS in ambient aerosol. Our results showed that the light absorption of HULIS appeared to increase with unsaturation degree, but decreased with oxidation level. The unsaturation of HULIS was affected by both sources and oxidation level. Even among HULIS with the same DBE values, the light absorption capacities may differ due to charge-transfer complexes (Phillips and Smith, 2014) and substituted functional groups (Sun et al., 2007), but these issues were not within the scope of our study. Additionally, fossil-derived OC appears to be more recalcitrant to atmospheric aging compared with non-fossil-derived OC. The relatively high fossil contribution of HULIS compared with non-HULIS indicates that these high MW compounds have longer-lived absorption capacities relative to low MW compounds, which may be important to their effects on climate and should be examined in future studies.

\section{Conclusions}

$\mathrm{BrC}$ is ubiquitous in the atmosphere and plays an important role in climate forcing, but only a very limited number of climate model studies have considered the evolution of $\mathrm{BrC}$ absorption in the atmosphere (Laskin et al., 2015; Lin et al., 2014). Because HULIS have been shown to be strongly related to $\mathrm{BrC}$, studying the relationships among the sources, compositions, and light-absorbing capacity of HULIS will improve our understanding of the evolution of $\mathrm{BrC}$ absorption. The short-term emissions reduction measures enacted during the APEC summit provided a good opportunity to investigate the response of HULIS light-absorbing capacity to their sources and compositions. Over the study period, HULIS contributed $58.7 \pm 11.5 \%$ of the WSOC, but accounted for $80.2 \pm 6.1 \%$ of the absorption by WSOC at $365 \mathrm{~nm}$. Compared to non-HULIS, HULIS had more depleted ${ }^{13} \mathrm{C}$ and ${ }^{14} \mathrm{C}$, indicating that the aging rate for fossilderived OC was lower than that of contemporary OC. The fraction of CHON compounds increased with non-fossil contribution during APEC, perhaps due to biomass burning or the shift in photooxidation chemistry to a different regime in response to massive reductions in NOx, whereas the higher fraction of S-containing compounds before and after APEC were more related to sulfur dioxide emitted from fossil fuel combustion. From the relationships between the sources, compositions, and optical properties of HULIS, we found that the unsaturation degree of HULIS was affected by both sources and oxidation level, and the absorption capacity of HULIS decreased with increasing oxidation, but 
increased with increasing unsaturation degree. Our results underscore the important roles of sources and atmospheric processes in the light absorption by BrC.

\section{Acknowledgements}

This study was supported by the Natural Science Foundation of China (NSFC; Grant Nos. 41430645 and 41773120), the Guangzhou Science and Technology Program key projects (No. 201504010002), and the "Strategic Priority Research Program (B)" of the Chinese Academy of Sciences (Grant No. XDB05040503). All FT-ICR MS data in this manuscript are freely available in the supporting information. This is contribution No.IS-2525 from GIGCAS.

\section{Appendix A. Supplementary data}

Supplementary data related to this article can be found at https://doi.org/10.1016/j.envpol.2018.04.041.

\section{References}

Aggarwal, S.G., Kawamura, K., 2008. Molecular distributions and stable carbon isotopic compositions of dicarboxylic acids and related compounds in aerosols from Sapporo, Japan: implications for photochemical aging during long-range atmospheric transport. J. Geophys. Res. Atmosphere 113.

Altieri, K., Turpin, B.J., Seitzinger, S., 2009. Oligomers, organosulfates, and nitrooxy organosulfates in rainwater identified by ultra-high resolution electrospray ionization FT-ICR mass spectrometry. Atmos. Chem. Phys. 9, 2533-2542.

Ancelet, T., Davy, P.K., Trompetter, W.J., Markwitz, A., Weatherburn, D.C., 2013. Carbonaceous aerosols in a wood burning community in rural New Zealand. Atmos. Pollut. Res. 4, 245-249.

Andersson, A., Deng, J., Du, K., Zheng, M., Yan, C., Sköld, M., Gustafsson, O.r., 2015. Regionally-varying combustion sources of the January 2013 severe haze events over eastern China. Environ. Sci. Technol. 49, 2038-2043.

Andreae, M.O., Gelencser, A., 2006. Black carbon or brown carbon? The nature of light-absorbing carbonaceous aerosols. Atmos. Chem. Phys. 6, 3131-3148.

Avery, G.B., Biswas, K.F., Mead, R., Southwell, M., Willey, J.D., Kieber, R.J., Mullaugh, K.M., 2013. Carbon isotopic characterization of hydrophobic dissolved organic carbon in rainwater. Atmos. Environ. 68, 230-234.

Bahadur, R., Praveen, P.S., Xu, Y., Ramanathan, V., 2012. Solar absorption by elemental and brown carbon determined from spectral observations. Proc. Natl. Acad. Sci. U. S. A. 109, 17366-17371.

Bosch, C., Andersson, A., Kirillova, E.N., Budhavant, K., Tiwari, S., Praveen, P. Russell, L.M., Beres, N.D., Ramanathan, V., Gustafsson, Ö., 2014. Source-diagnostic dual-isotope composition and optical properties of water-soluble organic carbon and elemental carbon in the South Asian outflow intercepted over the Indian Ocean. J. Geophys. Res. Atmosphere 119.

Cao, J.-J., Chow, J.C., Tao, J., Lee, S.-C., Watson, J.G., Ho, K.-f., Wang, G.-H., Zhu, C.-S., Han, Y.-M., 2011. Stable carbon isotopes in aerosols from Chinese cities: influence of fossil fuels. Atmos. Environ. 45, 1359-1363.

Cavalli, F., Viana, M., Yttri, K.E., Genberg, J., Putaud, J.-P., 2010. Toward a standardised thermal-optical protocol for measuring atmospheric organic and elemental carbon: the EUSAAR protocol. Atmos. Meas. Tech. 3, 79-89.

Chang, J.L., Thompson, J.E., 2010. Characterization of colored products formed during irradiation of aqueous solutions containing $\mathrm{H} 2 \mathrm{O} 2$ and phenolic compounds. Atmos. Environ. 44, 541-551.

Chen, Q., Ikemori, F., Higo, H., Asakawa, D., Mochida, M., 2016a. Chemical structural characteristics of HULIS and other fractionated organic matter in urban aerosols: results from mass spectral and FT-IR analysis. Environ. Sci. Technol. 50, 1721-1730.

Chen, Q. Ikemori, F., Mochida, M., 2016b. Light absorption and excitation-emission fluorescence of urban organic aerosol components and their relationship to chemical structure. Environ. Sci. Technol. 50, 10859-10868.

Chen, Y., Bond, T.C., 2010. Light absorption by organic carbon from wood combustion. Atmos. Chem. Phys. 10, 1773-1787.

Cheng, Y., He, K.-b., Du, Z.-y., Engling, G., Liu, J.-m., Ma, Y.-l., Zheng, M., Weber, R.J., 2016. The characteristics of brown carbon aerosol during winter in Beijing. Atmos. Environ. 127, 355-364.

Cheng, Y., He, K.-B., Zheng, M., Duan, F.-K., Du, Z.-Y., Ma, Y.-L., Tan, J.-H., Yang, F.-M., Liu, J.-M., Zhang, X.-L., 2011. Mass absorption efficiency of elemental carbon and water-soluble organic carbon in Beijing, China. Atmos. Chem. Phys. 11, 11497-11510.

Chung, C.E., Ramanathan, V., Decremer, D., 2012. Observationally constrained estimates of carbonaceous aerosol radiative forcing. Proc. Natl. Acad. Sci. Unit. States Am. 109, 11624-11629.

Dai, S., Bi, X., Chan, L., He, J., Wang, B., Wang, X., Peng, P., Sheng, G., Fu, J., 2015. Chemical and stable carbon isotopic composition of PM 2.5 from on-road vehicle emissions in the PRD region and implications for vehicle emission control policy. Atmos. Chem. Phys. 15, 3097-3108.

Di Lorenzo, R.A., Young, C.J., 2016. Size separation method for absorption characterization in brown carbon: application to an aged biomass burning sample. Geophys. Res. Lett. 43, 458-465.

Di Lorenzo, R.A., Washenfelder, R.A., Attwood, A.R., Guo, H., Xu, L., Ng, N.L., Weber, R.J., Baumann, K., Edgerton, E.S., Young, C.J., 2017. Molecular size separated brown carbon absorption for biomass burning aerosol at multiple field sites. Environ. Sci. Technol. 51, 3128-3137.

Du, Z., He, K., Cheng, Y., Duan, F., Ma, Y., Liu, J., Zhang, X., Zheng, M., Weber, R., 2014 A yearlong study of water-soluble organic carbon in Beijing I: sources and its primary vs. secondary nature. Atmos. Environ. 92, 514-521.

Ervens, B., Turpin, B., Weber, R., 2011. Secondary organic aerosol formation in cloud droplets and aqueous particles (aqSOA): a review of laboratory, field and model studies. Atmos. Chem. Phys. 11, 11069-11102.

Harrison, M.A., Barra, S., Borghesi, D., Vione, D., Arsene, C., Olariu, R.I., 2005 Nitrated phenols in the atmosphere: a review. Atmos. Environ. 39, 231-248.

Hecobian, A., Zhang, X., Zheng, M., Frank, N., Edgerton, E.S., Weber, R.J., 2010. WaterSoluble Organic Aerosol material and the light-absorption characteristics of aqueous extracts measured over the Southeastern United States. Atmos. Chem. Phys. 10, 5965-5977.

Hinrichs, R.Z., Buczek, P., Trivedi, J., 2016. Solar absorption by aerosol bound nitrophenols compared to aqueous and gaseous nitrophenols. Environ. Sci. Technol. 50, 5661-5667.

Hoffer, A., Gelencsér, A., Guyon, P., Kiss, G., Schmid, O., Frank, G., Artaxo, P. Andreae, M., 2006. Optical properties of humic-like substances (HULIS) in biomass-burning aerosols. Atmos. Chem. Phys. 6, 3563-3570.

Holmes, B.J., Petrucci, G.A., 2006. Water-soluble oligomer formation from acidcatalyzed reactions of levoglucosan in proxies of atmospheric aqueous aerosols. Environ. Sci. Technol. 40, 4983-4989.

Jiang, B., Kuang, B., Liang, Y., Zhang, J., Huang, H., Xu, C., Yu, J.Z., Shi, Q., 2016. Molecular composition of urban organic aerosols on clear and hazy days in beijing: a comparative study using FT-ICR MS. Environ. Chem. 13, 888-901.

Jps, W., Nenes, A., Weber, R.J., 2017. Changes in light absorptivity of molecular weight separated Brown carbon due to photolytic aging. Environ. Sci. Technol. $51,8414-8421$.

Kirillova, E.N., Andersson, A., Han, J., Lee, M., Gustafsson, Ö., 2014a. Sources and light absorption of water-soluble organic carbon aerosols in the outflow from northern China. Atmos. Chem. Phys. 14, 1413-1422.

Kirillova, E.N., Andersson, A., Sheesley, R.J., Krusă, M., Praveen, P., Budhavant, K., Safai, P., Rao, P., Gustafsson, Ö., 2013. 13C-and 14C-based study of sources and atmospheric processing of water-soluble organic carbon (WSOC) in South Asian aerosols. J. Geophys. Res. Atmosphere 118, 614-626.

Kirillova, E.N., Andersson, A., Tiwari, S., Srivastava, A.K., Bisht, D.S., Gustafsson, Ö. 2014b. Water-soluble organic carbon aerosols during a full New Delhi winter: isotope-based source apportionment and optical properties. J. Geophys. Res. Atmosphere 119, 3476-3485.

Koch, B.P., Dittmar, T., 2006. From mass to structure: an aromaticity index for highresolution mass data of natural organic matter. Rapid Commun. Mass Spectrom. 20, 926-932.

Kramer, R.W., Kujawinski, E.B., Hatcher, P.G., 2004. Identification of black carbon derived structures in a volcanic ash soil humic acid by Fourier transform ion cyclotron resonance mass spectrometry. Environ. Sci. Technol. 38, 3387-3395.

Kuang, B.Y., Lin, P., Huang, X.H.H., Yu, J.Z., 2015. Sources of humic-like substances in the Pearl River Delta, China: positive matrix factorization analysis of PM 2.5 major components and source markers. Atmos. Chem. Phys. 15, 1995-2008.

Kundu, S., Fisseha, R., Putman, A.L., Rahn, T.A., Mazzoleni, L., 2012. High molecular weight SOA formation during limonene ozonolysis: insights from ultrahighresolution FT-ICR mass spectrometry characterization. Atmos. Chem. Phys. 12, 5523-5536.

Lambe, A.T., Cappa, C.D., Massoli, P., Onasch, T.B., Forestieri, S.D., Martin, A.T., Cummings, M.J., Croasdale, D.R., Brune, W.H., Worsnop, D.R., 2013. Relationship between oxidation level and optical properties of secondary organic aerosol. Environ. Sci. Technol. 47, 6349-6357.

Laskin, A., Laskin, J., Nizkorodov, S.A., 2015. Chemistry of atmospheric brown carbon. Chem. Rev. 115, 4335-4382.

Laskin, A., Smith, J.S., Laskin, J., 2009. Molecular characterization of nitrogencontaining organic compounds in biomass burning aerosols using highresolution mass spectrometry. Environ. Sci. Technol. 43, 3764-3771.

Lee, H.J., Aiona, P.K., Laskin, A., Laskin, J., Nizkorodov, S.A., 2014. Effect of solar radiation on the optical properties and molecular composition of laboratory proxies of atmospheric brown carbon. Environ. Sci. Technol. 48, 10217-10226.

Levin, I., Kromer, B., 2004. The tropospheric 14CO2 level in mid latitudes of the northern hemisphere (1959-2003). Radiocarbon 46, 1261-1271.

Levin, I., Kromer, B., Hammer, S., 2013. Atmospheric $\Delta 14$ CO 2 trend in Western European background air from 2000 to 2012. Tellus B 65.

Li, C., Yan, F., Kang, S., Chen, P., Hu, Z., Gao, S., Qu, B., Sillanpää, M., 2016. Light absorption characteristics of carbonaceous aerosols in two remote stations of the southern fringe of the Tibetan Plateau, China. Atmos. Environ. 143, 79-85.

Li, J., Xie, S., Zeng, L., Li, L., Li, Y., Wu, R., 2015. Characterization of ambient volatile organic compounds and their sources in Beijing, before, during, and after AsiaPacific Economic Cooperation China 2014. Atmos. Chem. Phys. 15, 7945-7959.

Lin, G.X., Penner, J.E., Flanner, M.G., Sillman, S., Xu, L., Zhou, C., 2014. Radiative forcing of organic aerosol in the atmosphere and on snow: effects of SOA and brown carbon. J. Geophys. Res. Atmos. 119, 7453-7476.

Lin, P., Aiona, P.K., Li, Y., Shiraiwa, M., Laskin, J., Nizkorodov, S.A., Laskin, A., 2016 
Molecular characterization of Brown carbon in biomass burning aerosol particles. Environ. Sci. Technol. 50, 11815-11824.

Lin, P., Engling, G., Yu, J.Z., 2010. Humic-like substances in fresh emissions of rice straw burning and in ambient aerosols in the Pearl River Delta Region, China. Atmos. Chem. Phys. 10, 6487-6500.

Lin, P., Rincon, A.G., Kalberer, M., Yu, J.Z., 2012. Elemental composition of HULIS in the Pearl River Delta Region, China: results inferred from positive and negative electrospray high resolution mass spectrometric data. Environ. Sci. Technol. 46, 7454-7462.

Liu, D., Li, J., Zhang, Y., Xu, Y., Liu, X., Ding, P., Shen, C., Chen, Y., Tian, C., Zhang, G., 2013. The use of levoglucosan and radiocarbon for source apportionment of PM2. 5 carbonaceous aerosols at a background site in East China. Environ. Sci. Technol. 47, 10454-10461.

Liu, H., He, J., Guo, J., Miao, Y., Yin, J., Wang, Y., Xu, H., Liu, H., Yan, Y., Li, Y., 2017. The blue skies in Beijing during APEC 2014: a quantitative assessment of emission control efficiency and meteorological influence. Atmos. Environ. 167, 235-244.

Liu, J., Li, J., Zhang, Y., Liu, D., Ding, P., Shen, C., Shen, K., He, Q., Ding, X., Wang, X. 2014. Source apportionment using radiocarbon and organic tracers for PM2. 5 carbonaceous aerosols in Guangzhou, South China: contrasting local-and regional-scale haze events. Environ. Sci. Technol. 48, 12002-12011.

Liu, J., Mo, Y., Li, J., Liu, D., Shen, C., Ding, P., Jiang, H., Cheng, Z., Zhang, X., Tian, C. 2016a. Radiocarbon-derived source apportionment of fine carbonaceous aerosols before, during, and after the 2014 Asia-Pacific Economic Cooperation (APEC) summit in Beijing, China. J. Geophys. Res. Atmosphere 121, 4177-4187.

Liu, J.M., Lin, P., Laskin, A., Laskin, J., Kathmann, S.M., Wise, M., Caylor, R., Imholt, F. Selimovic, V., Shilling, J.E., 2016b. Optical properties and aging of lightabsorbing secondary organic aerosol. Atmos. Chem. Phys. 16, 12815-12827.

Mazzoleni, L.R., Ehrmann, B.M., Shen, X., Marshall, A.G., Collett Jr., J.L., 2010. Watersoluble atmospheric organic matter in fog: exact masses and chemical formula identification by ultrahigh-resolution Fourier transform ion cyclotron resonance mass spectrometry. Environ. Sci. Technol. 44, 3690-3697.

Miyazaki, Y., Kondo, Y., Takegawa, N., Komazaki, Y., Fukuda, M., Kawamura, K., Mochida, M., Okuzawa, K., Weber, R., 2006. Time-resolved measurements of water-soluble organic carbon in Tokyo. J. Geophys. Res. Atmosphere 111.

Mo, Y., Li, J., Liu, J., Zhong, G., Cheng, Z., Tian, C., Chen, Y., Zhang, G., 2017. The influence of solvent and $\mathrm{pH}$ on determination of the light absorption properties of water-soluble brown carbon. Atmos. Environ. 161, 90-98.

Nakayama, T., Matsumi, Y., Sato, K., Imamura, T., Yamazaki, A., Uchiyama, A., 2010. Laboratory studies on optical properties of secondary organic aerosols generated during the photooxidation of toluene and the ozonolysis of $\alpha$-pinene. J. Geophys. Res.: Atmosphere 115.

Ng, N.L., Brown, S.S., Archibald, A.T., Atlas, E., Cohen, R.C., Crowley, J.N., Day, D.A., Donahue, N.M., Fry, J.L., Fuchs, H., 2017. Nitrate radicals and biogenic volatile organic compounds: oxidation, mechanisms, and organic aerosol. Atmos. Chem. Phys. 17, 2103-2162.

Park, S.S., Yu, J., 2016. Chemical and light absorption properties of humic-like substances from biomass burning emissions under controlled combustion experiments. Atmos. Environ. 136, 114-122.

Pavuluri, C.M., Kawamura, K., 2016. Enrichment of 13C in diacids and related compounds during photochemical processing of aqueous aerosols: new proxy for organic aerosols aging. Sci. Rep. 6.

Phillips, S.M., Bellcross, A.D., Smith, G.D., 2017. Light absorption by Brown carbon in the southeastern United States is pH-dependent. Environ. Sci. Technol. 51, 6782-6790.

Phillips, S.M., Smith, G.D., 2014. Light absorption by charge transfer complexes in brown carbon aerosols. Environ. Sci. Technol. Lett. 1, 382-386.

Qiao, T., Zhao, M., Xiu, G., Yu, J., 2015. Seasonal variations of water soluble composition (WSOC, Hulis and WSIIs) in PM 1 and its implications on haze pollution in urban Shanghai, China. Atmos. Environ. 123, 306-314.

Riva, M., Tomaz, S., Cui, T., Lin, Y.-H., Perraudin, E., Gold, A., Stone, E.A., Villenave, E., Surratt, J.D., 2015. Evidence for an unrecognized secondary anthropogenic source of organosulfates and sulfonates: gas-phase oxidation of polycyclic aromatic hydrocarbons in the presence of sulfate aerosol. Environ. Sci. Technol. 49, 6654-6664.

Rodgers, R.P. Marshall, A.G., 2007. Petroleomics: Advanced Characterization of Petroleum-derived Materials by Fourier Transform Ion Cyclotron Resonance Mass Spectrometry (FT-icr MS), Asphaltenes, Heavy Oils, and Petroleomics. Springer, pp. 63-93.

Rollins, A., Browne, E., Min, K.-E., Pusede, S., Wooldridge, P., Gentner, D. Goldstein, A., Liu, S., Day, D., Russell, L., 2012. Evidence for NOx control over nighttime SOA formation. Science 337, 1210-1212.

Rudolph, J., Czuba, E., Huang, L., 2000. The stable carbon isotope fractionation for reactions of selected hydrocarbons with $\mathrm{OH}$-radicals and its relevance for atmospheric chemistry. J. Geophys. Res. Atmosphere 105, 29329-29346.

Saleh, R., Hennigan, C., McMeeking, G., Chuang, W., Robinson, E., Coe, H., Donahue, N., Robinson, A., 2013. Absorptivity of brown carbon in fresh and photo-chemically aged biomass-burning emissions. Atmos. Chem. Phys. 13, 7683-7693.
Saleh, R., Robinson, E.S., Tkacik, D.S., Ahern, A.T., Liu, S., Aiken, A.C., Sullivan, R.C., Presto, A.A., Dubey, M.K., Yokelson, R.J., 2014. Brownness of organics in aerosols from biomass burning linked to their black carbon content. Nat. Geosci. 7, $647-650$.

Sheesley, R.J., Kirillova, E., Andersson, A., Kruså, M., Praveen, P., Budhavant, K., Safai, P.D., Rao, P., Gustafsson, Ö., 2012. Year-round radiocarbon-based source apportionment of carbonaceous aerosols at two background sites in South Asia. J. Geophys. Res.: Atmosphere 117.

Smith, J.S., Laskin, A., Laskin, J., 2009. Molecular characterization of biomass burning aerosols using high-resolution mass spectrometry. Anal. Chem. 81, 1512-1521.

Song, J., He, L., Peng, P.a., Zhao, J., Ma, S., 2012. Chemical and isotopic composition of humic-like substances (HULIS) in ambient aerosols in Guangzhou, South China. Aerosol. Sci. Technol. 46, 533-546.

Srinivas, B., Rastogi, N., Sarin, M., Singh, A., Singh, D., 2016. Mass absorption efficiency of light absorbing organic aerosols from source region of paddy-residue burning emissions in the Indo-Gangetic Plain. Atmos. Environ. 125, 360-370.

Sun, H., Biedermann, L., Bond, T.C., 2007. Color of brown carbon: a model for ultraviolet and visible light absorption by organic carbon aerosol. Geophys. Res. Lett. 34.

Surratt, J.D. Gómez-González, Y., Chan, A.W., Vermeylen, R., Shahgholi, M. Kleindienst, T.E., Edney, E.O., Offenberg, J.H., Lewandowski, M., Jaoui, M., 2008. Organosulfate formation in biogenic secondary organic aerosol. J. Phys. Chem. $112,8345-8378$

Szidat, S., 2009. Atmosphere. Sources of asian haze. Science 323, 470-471.

Szidat, S., Jenk, T.M., Gäggeler, H.W., Synal, H.-A., Fisseha, R., Baltensperger, U., Kalberer, M., Samburova, V., Reimann, S., Kasper-Giebl, A., 2004. Radiocarbon (14 C)-deduced biogenic and anthropogenic contributions to organic carbon (OC) of urban aerosols from Zürich, Switzerland. Atmos. Environ. 38, 4035-4044.

Tao, S., Lu, X., Levac, N., Bateman, A.P., Nguyen, T.B., Bones, D.L., Nizkorodov, S.A., Laskin, J., Laskin, A., Yang, X., 2014. Molecular characterization of organosulfates in organic aerosols from Shanghai and Los Angeles urban areas by nanospraydesorption electrospray ionization high-resolution mass spectrometry. Environ. Sci. Technol. 48, 10993-11001.

Varga, B., Kiss, G., Ganszky, I., Gelencsér, A., Krivácsy, Z., 2001. Isolation of watersoluble organic matter from atmospheric aerosol. Talanta 55, 561-572.

Wang, G., Yao, J., Zeng, Y., Huang, Y., Qian, Y., Liu, W., Li, Y., Yuan, N., Liu, S., Shan, J., 2013. Source apportionment of carbonaceous particulate matter in a Shanghai suburb based on carbon isotope composition. Aerosol. Sci. Technol. 47, 239-248.

Wang, H. Kawamura, K., 2006. Stable carbon isotopic composition of lowmolecular-weight dicarboxylic acids and ketoacids in remote marine aerosols. J. Geophys. Res.: Atmosphere 111.

Wang, J., Wang, G., Gao, J., Wang, H., Ren, Y., Li, J., Zhou, B., Wu, C., Zhang, L., Wang, S., 2017. Concentrations and stable carbon isotope compositions of oxalic acid and related SOA in Beijing before, during, and after the 2014 APEC. Atmos. Chem. Phys. 17, 1-32.

Wang, Z., Bai, Y., Zhang, S., 2003. A biogenic volatile organic compounds emission inventory for Beijing. Atmos. Environ. 37, 3771-3782.

Wang, Z.S., Li, Y.T., Chen, T., Li, L.J., Liu, B.X., Zhang, D.W., Sun, F., Wei, Q., Jiang, L., Pan, L.B., 2015. Changes in atmospheric composition during the 2014 APEC conference in Beijing. J. Geophys. Res. Atmos. 120, 12695-12707.

Wozniak, A., Willoughby, A., Gurganus, S., Hatcher, P.G., 2014. Distinguishing molecular characteristics of aerosol water soluble organic matter from the 2011 trans-North Atlantic US GEOTRACES cruise. Atmos. Chem. Phys. 14, 8419-8434.

Xu, W., Sun, Y., Chen, C., Du, W., Han, T., Wang, Q., Fu, P., Wang, Z., Zhao, X., Zhou, L., 2015. Aerosol composition, oxidation properties, and sources in Beijing: results from the 2014 Asia-Pacific Economic Cooperation summit study. Atmos. Chem. Phys. 15, 13681-13698.

Yu, L., Smith, J., Laskin, A., George, K.M., Anastasio, C., Laskin, J., Dillner, A.M., Zhang, Q., 2016. Molecular transformations of phenolic SOA during photochemical aging in the aqueous phase: competition among oligomerization, functionalization, and fragmentation. Atmos. Chem. Phys. 16, 4511-4527.

Zhang, X., Lin, Y.-H., Surratt, J.D., Weber, R.J., 2013. Sources, composition and absorption Ångstrom exponent of light-absorbing organic components in aerosol extracts from the Los Angeles Basin. Environ. Sci. Technol. 47, 3685-3693.

Zhang, X., Lin, Y.H., Surratt, J.D., Zotter, P., Prévôt, A.S., Weber, R.J., 2011. Lightabsorbing soluble organic aerosol in Los Angeles and Atlanta: a contrast in secondary organic aerosol. Geophys. Res. Lett. 38.

Zhao, M., Huang, Z., Qiao, T., Zhang, Y., Xiu, G., Yu, J., 2015a. Chemical characterization, the transport pathways and potential sources of PM 2.5 in Shanghai: seasonal variations. Atmos. Res. 158, 66-78.

Zhao, R., Lee, A., Huang, L., Li, X., Yang, F., Abbatt, J., 2015b. Photochemical processing of aqueous atmospheric brown carbon. Atmos. Chem. Phys. 15, 6087-6100.

Zhong, M., Jang, M., 2014. Dynamic light absorption of biomass-burning organic carbon photochemically aged under natural sunlight. Atmos. Chem. Phys. 14, 1517-1525. 